\title{
Psychosocial Factors Associated with Smoking Cessation Attempts in Korean High School Students Who Engage in Intermittent and Light Smoking
}

\author{
Jin Suk $\mathrm{Ra}^{1}$, Yeon-Hee Jeong ${ }^{2}$ \\ ${ }^{1}$ Associate Professor, College of Nursing, Chungnam National University, Daejeon; ${ }^{2}$ Doctoral Student, College of Nursing, Chungnam National University, \\ Daejeon, Korea
}

Purpose: This study aimed to identify psychosocial factors associated with smoking cessation attempts among Korean high school students who engage in intermittent and light smoking. Methods: Cross-sectional secondary data derived from the 2018 Korea Youth Risk Behavior Web-Based Survey were analyzed within the framework of the biopsychosocial model. The sample comprised 829 high school students who reported current intermittent and light smoking, which was defined as cigarette smoking on 1 29 days in a 30-day period and no more than 10 cigarettes per day. Purposeful selection logistic regression analysis was performed. Results: In total, $71.7 \%(n=586)$ of the respondents had tried to stop smoking during the past 12 months. The main result was that respondents who had viewed an anti-smoking advertisement in the past year significantly more smoking cessation attempts than those who had not (adjusted odds ratio=2.59; 95\% confidence interval=1.45 4.62, $p=.001$ ). Conclusion: To encourage smoking cessation attempts among high school students who engage in intermittent and light smoking, healthcare providers, including school and community nurses, should develop effective interventions using anti-smoking advertisements tailored to adolescents' interests and developmental stage.

Key words: Student; Smoking; Smoking cessation

\section{Corresponding author Yeon-Hee Jeong \\ https://orcid.org/0000-0001-5712-6657}

College of Nursing, Chungnam National University, 266 Munhwa-ro, Jung-gu, Daejeon 35015, Korea

TEL +82-42-538-8333 FAX +82-42-580-8309

E-MAIL yeonhee389@naver.com

Received Jul 9, 2019 Revised Aug 8, 2019 Accepted Sep 7, 2019 (a) This is an Open Access article distributed under the terms of the Creative Commons Attribution NonCommercial License (http://creativecommons.org/licenses/by-nc/4.0/) which permits unrestricted noncommercial use, distribution, and reproduction in any medium, provided the original work is properly cited.

\section{INTRODUCTION}

Smoking is a prevalent behavioral threat to public health for both adults and children [1]. Smoking tends to be initiated during adolescence, and roughly $87 \%$ of the smokers in the United States began smoking before they were 18 years old [1]. In 2017, the average age of smoking initiation was 13 years old during middle school [2]. In Korea, the prevalence of cigarette smoking among high school students in 2017 was 14.1\% among males and 5.1\% among females, and cigarette smoking prevalence has gradually increased among high school students since 2016 [2]. In addition, approximately $80 \%$ of adolescent smokers were found to be high school students [2]. Thus, high school students might be the primary target group for smoking cessation interventions aiming to reduce the prevalence of smoking among adolescents. Furthermore, among adolescent smokers, intermittent (non-daily) and light (10 or fewer cigarettes per day) smoking is the most prevalent smoking pattern in the United States and Korea, and this pattern might be becoming increasingly common [3,4]. The prevalence of intermittent and light smoking among Korean adolescents is higher than in other Asian countries, such as China [5].

Despite the high prevalence of this pattern of smoking, adolescent intermittent and light smokers tend to underestimate 
the harm caused by their smoking compared to their counterparts who are daily or heavy smokers (more than 10 cigarettes per day) [3]. Nonetheless, intermittent and light smoking increases the risks of cancer, cardiovascular disease, and respiratory symptoms [6]. Often, adolescents who are intermittent and light smokers tend to be treated like non-smokers [7]. Consequently, they might not choose to participate in smoking cessation programs or to seek help from healthcare providers for smoking cessation [7]. Cigarette smoking tends to follow a trajectory from never smoking to daily smoking due to nicotine addiction, and intermittent and light smoking might be easier to quit than daily or heavy smoking because the withdrawal symptoms are less severe [8].

Previous studies have found that intermittent and light smokers were more likely than daily smokers to attempt to quit and to successfully complete cessation programs [9]. Thus, modifiable factors-particularly psychosocial factors-associated with smoking cessation attempts and smoking cessation programs might be important ways to lower adolescents' smoking prevalence. For example, a stronger intention to smoke among intermittent or light adolescent smokers tends to relate to psychological states, such as temporary emotional stress or having friends who smoke $[5,10]$. A previous study found that the smoking intentions of intermittent and light adolescent smokers were restrained by adolescents' negative social perceptions and attitudes toward smoking [4]. Thus, determining the psychosocial factors associated with smoking cessation might assist in the development of tailored interventions that help adolescents who are intermittent and light smokers to quit.

To date, few studies have attempted to determine factors associated with intermittent and light smoking among Korean adolescents [4], and the identification of significant modifiable psychosocial factors has been limited. According to Wang et al. [5], smoking is a chronic behavioral disease influenced by biological, psychological, and sociological characteristics. Thus, the biopsychosocial model has been considered to be a suitable framework for identifying various factors associated with health-related behaviors on multiple levels [11]; in previous studies, biopsychosocial models of health-related behaviors regarding adolescents' smoking and smoking intentions found a variety of relevant individual psychological characteristics and sociocultural environments $[4,11]$.

Similarly, adolescents' smoking cessation attempts might be associated with diverse psychosocial factors. Previous studies have found that certain biological factors in girls and young adolescents were associated with increased smoking cessation attempts [12]. In terms of psychological factors, adolescents with a perceived skinny body type [12,13] and low levels of subjective stress [13] were more likely to try smoking cessation. In addition, the absence of current depressive symptoms $[10,13,14]$, not having any experience of alcohol consumption [12,15], and engaging in vigorous physical activity $[10,13,14]$ have been found to be positively related to adolescents' smoking cessation attempts. In another previous study, health-related behaviors, including physical activity, were categorized as psychological factors associated with smoking and chronic diseases caused by smoking [16]. Of the relevant social factors, adolescents who experienced difficulty purchasing cigarettes might have made more smoking cessation attempts than adolescents who easily purchased cigarettes $[12,13]$. In addition, adolescents who viewed anti-smoking advertisements [10,12,14,15], participated in school-based anti-smoking programs [10,12-15], saw warning labels on cigarette packets [17], or experienced passive smoking at home, school, or in public places $[12,15]$ made more smoking cessation attempts than their counterparts. Additionally, adolescents without a currently smoking father and/or mother [13], sibling smokers [12,13], or close friends who smoked [10,12-15] might make more smoking cessation attempts than adolescents with familial or personal relationships with current smokers. Furthermore, those with higher perceived academic achievement [14] and higher perceived family socioeconomic status [13] might make more smoking cessation attempts. Therefore, this study aimed to identify the psychosocial factors associated with smoking cessation attempts by high school students who were intermittent and light smokers, based on the psychosocial factors that previous studies found to be associated with heavier smokers' cessation attempts. Finally, this study may contribute to the development of interventions focused on the psychosocial characteristics associated with smoking cessation attempts among Korean adolescents who engage in intermittent and light smoking.

\section{METHODS}

\section{Study Design and Sample}

This cross-sectional study used secondary data derived from the 2018 Korea Youth Risk Behavior Web-Based Survey (KYRBS) [2]. The KYRBS is an online annual cross-sectional survey intended to monitor Korean adolescents'(middle school and high school students) health-related behaviors. In 2018 , the KYRBS sampled 62,823 adolescents at 800 schools in 17 Korean provinces. Of them, 60,040 (95.6\%) responded, and 29,811 of the respondents were high school students. The data used in this study were drawn from the 829 high school students who reported being current intermittent and light smokers and answered the survey questions on the relevant psychosocial factors. 


\section{Variables}

\section{1) Smoking cessation attempts (dependent variable)}

Smoking cessation attempts were measured using responses to the question, "Have you tried to stop smoking during the past 12 months?" The response options were "yes" or "no."

\section{2) Biological, psychological, and social factors (independent variables)}

The two biological, five psychological, and thirteen social factors analyzed in this study are described in Table 1.

\section{Methods of Data Analysis}

SPSS version 24.0 (IBM Corp., Armonk, NY, USA) was used to perform the statistical analyses following the guidelines proposed by the 2018 KYRBS [2]. First, descriptive statistics were calculated to analyze the distribution of the independent variables. Then, purposeful selection logistic regression analysis was performed to elucidate the influence of psychosocial factors on smoking cessation attempts following the steps recommended by Bursac, Gauss, Williams, and Hosmer [18]. The purposeful selection of variables for the logistic regression analysis utilized supplementation for numerically unstable estimates and large standard errors estimated by the logistic regression analysis, which includes all variables in a model regardless of the variables' significance [18]. The purposeful selection of variables began by performing a bivariate analysis of each variable. Significant variables $(p<.250)$ in the bivariate analysis were included in the multivariate analysis [18]. Bursac et al. [18] proposed a $p$-value cutoff value of .250 because the conventional cutoff point of .050 might miss important variables. Then, $p<.050$ (two-tailed tests of significance) was the cut-off level applied to the results of the multivariate analysis.

Thus, in the first step of bivariate analysis, the relationships of independent variables to whether smoking cessation attempts had been made in the past 12 months were separately assessed (generating bivariate odds ratios). The second step (multivariate analysis) incorporated all the statistically significant variables together in a binomial logistic regression analysis that generated multivariate odds ratios [18].

\section{RESULTS}

\section{Smoking Cessation Attempts}

In total, $71.7 \%(n=586)$ of the respondents reported that they had tried to stop smoking during the past 12 months.

\section{Biological, Psychological, and Social Characteristics}

Table 2 presents data on the biological, psychological, and social factors analyzed in the study. Males accounted for the majority of the sample $(66.4 \%)$, and the third grade of high school $(43.8 \%)$ was the most common grade. Regarding psychological characteristics, $40.3 \%$ of the sample perceived their body size as plump. High (47.4\%) and low (35.8\%) subjective stress were the most common responses to the question about stress, and $37.8 \%$ of the respondents reported depressive symptoms during the past year. Almost three-quarters (72.5\%) of the respondents had used alcohol during the past 30 days, and a large majority of the respondents $(81.5 \%)$ reported vigorous physical activity during the past 7 days.

Regarding social characteristics, a substantial number of high school students-albeit still a minority-reported that they had bought cigarettes either easily (15.5\%) or not easily $(29.0$ $\%$ ) during the past 30 days. A large proportion of the sample (81.6\%) had viewed an anti-smoking advertisement in the past year, $71.7 \%$ had participated in a school-based antismoking program in the past year, and most of them $(88.2 \%)$ reported they had read a warning label on a pack of cigarettes during the past 30 days. Furthermore, $34.3 \%$ of the sample reported passive smoking in their homes, $43.5 \%$ reported it at school, and $71.1 \%$ reported it in public places during the past 7 days. Moreover, $46.8 \%$ reported having fathers who currently smoked, $4.5 \%$ of them reported having mothers who currently smoked, and $12.8 \%$ of the sample reported that a sibling currently smoked. The percentage of the respondents with close friends who smoked was $94.5 \%$. Almost half of the respondents believed that their academic achievement during the past 12 months was low (47.8\%) and that their family's socioeconomic status was in the middle (46.1\%).

\section{Biological, Psychological, and Social Factors Associated with Smoking Cessation Attempts}

In the bivariate analyses, the biological factors of gender and age (i.e., high school grade) revealed $p$-values $<.250$ in association with smoking cessation attempts, while of the psychological factors, subjective stress, depressive symptoms, and vigorous physical activity presented $p$-values $<.250$. The social factors of having viewed an anti-smoking advertisement, having participated in a school-based anti-smoking program, having experienced passive smoking at school or in public places, having a close friend who was a current smoker, and perceived family socioeconomic status showed $p$-values $<.250$ for their associations with smoking cessation attempts.

In particular, having no depressive symptoms (odds ratio $[\mathrm{OR}]=0.68$; 95\% CI=0.49 0.93, $p=.015)$ decreased the like- 
Table 1. Measurements of Biological, Psychological, and Social Factors

\begin{tabular}{|c|c|c|c|}
\hline Variables & & Item & Response options* \\
\hline \multirow[t]{2}{*}{ Biological factors } & Gender & "What is your gender?" & $\begin{array}{l}\text { Boy } \\
\text { Girl }\end{array}$ \\
\hline & Grade & "What grade are you in?" & $\begin{array}{l}1 \text { st } \\
\text { 2nd } \\
\text { 3rd }\end{array}$ \\
\hline \multirow[t]{5}{*}{$\begin{array}{l}\text { Psychological } \\
\text { factors }\end{array}$} & Perceived body size & “How do you perceive your body size?" & $\begin{array}{l}\text { Skinny ("very skinny" and "a little skinny") } \\
\text { Normal } \\
\text { Plump ("very plump" and "a little plump") }\end{array}$ \\
\hline & Subjective stress & "How high is your stress level?" & $\begin{array}{l}\text { High ("extremely high" and "high") } \\
\text { Low } \\
\text { No ("almost none" and "none at all") }\end{array}$ \\
\hline & Depressive symptoms & $\begin{array}{l}\text { "During the past } 12 \text { months, have you felt } \\
\text { sad enough during any two-week period to } \\
\text { end your life?" }\end{array}$ & $\begin{array}{l}\text { Yes } \\
\text { No }\end{array}$ \\
\hline & Alcohol consumption & $\begin{array}{l}\text { "How many days did you drink alcohol } \\
\text { during the past } 30 \text { days?" }\end{array}$ & $\begin{array}{l}\text { Yes ("more than one day") } \\
\text { No }\end{array}$ \\
\hline & $\begin{array}{l}\text { Vigorous physical } \\
\text { activity }\end{array}$ & $\begin{array}{l}\text { "How many of the past } 7 \text { days did you have } \\
\text { more than } 20 \text { minutes of vigorous physical } \\
\text { activity?" }\end{array}$ & $\begin{array}{l}\text { Yes ("more than one day") } \\
\text { No ("no days") }\end{array}$ \\
\hline \multirow[t]{13}{*}{ Social factors } & $\begin{array}{l}\text { Ease of purchasing } \\
\text { cigarettes }\end{array}$ & $\begin{array}{l}\text { "Was it easy for you to buy cigarettes during } \\
\text { the past } 30 \text { days?" }\end{array}$ & $\begin{array}{l}\text { Never tried } \\
\text { Impossible } \\
\text { Not easy ("a little effort" and "much effort") } \\
\text { Easy }\end{array}$ \\
\hline & $\begin{array}{l}\text { Viewed an anti-smoking } \\
\text { advertisement }\end{array}$ & $\begin{array}{l}\text { "Have you seen or heard an anti-smoking } \\
\text { advertisement during the past } 12 \text { months?" } \\
\text { (on television, radio, and so on) }\end{array}$ & $\begin{array}{l}\text { Yes } \\
\text { No }\end{array}$ \\
\hline & $\begin{array}{l}\text { Participated in school- } \\
\text { based anti-smoking } \\
\text { program }\end{array}$ & $\begin{array}{l}\text { “During the past } 12 \text { months, have you been } \\
\text { in any educational activity at school about } \\
\text { smoking prevention and cessation?" }\end{array}$ & $\begin{array}{l}\text { Yes } \\
\text { No }\end{array}$ \\
\hline & $\begin{array}{l}\text { Read a warning label on a } \\
\text { pack of cigarettes }\end{array}$ & $\begin{array}{l}\text { "Have you seen a warning label on a pack of } \\
\text { cigarettes during the past } 30 \text { days?" }\end{array}$ & $\begin{array}{l}\text { Yes } \\
\text { No }\end{array}$ \\
\hline & Passive smoking at home & $\begin{array}{l}\text { "How many of the past } 7 \text { days have you } \\
\text { experienced passive smoking at home?" }\end{array}$ & $\begin{array}{l}\text { Yes ("more than one day") } \\
\text { No ("none") }\end{array}$ \\
\hline & Passive smoking at school & $\begin{array}{l}\text { "How many of the past } 7 \text { days have you } \\
\text { experienced passive smoking at school?" }\end{array}$ & $\begin{array}{l}\text { Yes ("more than one day") } \\
\text { No ("none") }\end{array}$ \\
\hline & $\begin{array}{l}\text { Passive smoking in public } \\
\text { places }\end{array}$ & $\begin{array}{l}\text { "How many of the past } 7 \text { days have you } \\
\text { experienced passive smoking in public } \\
\text { places" }\end{array}$ & $\begin{array}{l}\text { Yes ("more than one day") } \\
\text { No ("none") }\end{array}$ \\
\hline & Father's current smoking & "Does your father currently smoke?" & $\begin{array}{l}\text { Yes } \\
\text { No }\end{array}$ \\
\hline & Mother's current smoking & "Does your mother currently smoke?" & $\begin{array}{l}\text { Yes } \\
\text { No }\end{array}$ \\
\hline & Sibling's current smoking & "Does a brother or sister currently smoke?" & $\begin{array}{l}\text { Yes } \\
\text { No }\end{array}$ \\
\hline & $\begin{array}{l}\text { Close friend's } \\
\text { current smoking }\end{array}$ & $\begin{array}{l}\text { "How many of your close friends smoke } \\
\text { cigarettes?" }\end{array}$ & $\begin{array}{l}\text { Yes ("some", "most", and "all") } \\
\text { No ("none") }\end{array}$ \\
\hline & $\begin{array}{l}\text { Perceived } \\
\text { academic achievement }\end{array}$ & $\begin{array}{l}\text { “In your opinion, how good was your } \\
\text { academic achievement during the past } 12 \\
\text { months?" }\end{array}$ & $\begin{array}{l}\text { High ("high" and "upper-middle") } \\
\text { Middle } \\
\text { Low ("lower-middle" and "low") }\end{array}$ \\
\hline & $\begin{array}{l}\text { Perceived family } \\
\text { socioeconomic status }\end{array}$ & $\begin{array}{l}\text { "In your opinion, what is your family's } \\
\text { socioeconomic status?" }\end{array}$ & $\begin{array}{l}\text { High ("high" and "upper-middle") } \\
\text { Middle } \\
\text { Low ("lower-middle" and "low") }\end{array}$ \\
\hline
\end{tabular}

*Variables were transformed for the analysis as indicated in parentheses. 
Table 2. Characteristics of Biological, Psychological, and Social Factors among Adolescents Who Engaged in Intermittent and Light Smoking

\begin{tabular}{|c|c|c|c|}
\hline Variables & & Categories & $\mathrm{n}^{*}(\%)^{\dagger}$ \\
\hline \multirow[t]{5}{*}{ Biological factors } & Gender & Boy & $538(66.4)$ \\
\hline & & Girl & $291(33.6)$ \\
\hline & Grade & 1st & $228(25.7)$ \\
\hline & & 2nd & $258(30.5)$ \\
\hline & & 3rd & $343(43.8)$ \\
\hline \multirow[t]{12}{*}{ Psychological factors } & Perceived body size & Skinny & $220(26.4)$ \\
\hline & & Normal & $273(33.3)$ \\
\hline & & Plump & $336(40.3)$ \\
\hline & Subjective stress & High & $397(47.4)$ \\
\hline & & Low & $299(35.8)$ \\
\hline & & No & $133(16.8)$ \\
\hline & Depressive symptoms (in the past year) & Yes & $324(37.8)$ \\
\hline & & No & $505(62.2)$ \\
\hline & Alcohol consumption (in the past 30 days) & Yes & $602(72.5)$ \\
\hline & & No & $227(27.5)$ \\
\hline & Vigorous physical activity (in the past 7 days) & Yes & $666(81.5)$ \\
\hline & & No & $163(18.5)$ \\
\hline \multirow[t]{30}{*}{ Social factors } & Ease of purchasing cigarettes (in the past 30 days) & Never tried & $390(47.0)$ \\
\hline & & Impossible & $71(8.5)$ \\
\hline & & Not easy & $240(29.0)$ \\
\hline & & Easy & $128(15.5)$ \\
\hline & Viewed an anti-smoking advertisement & Yes & $671(81.6)$ \\
\hline & (in the past year) & No & $158(18.4)$ \\
\hline & Participated in school-based anti-smoking program & Yes & $602(71.7)$ \\
\hline & (in the past year) & No & $227(28.3)$ \\
\hline & Read a warning label on a pack of cigarettes & Yes & $734(88.2)$ \\
\hline & (in the past 30 days) & No & $95(11.8)$ \\
\hline & Passive smoking at home (in the past 7 days) & Yes & $287(34.3)$ \\
\hline & & No & $542(65.7)$ \\
\hline & Passive smoking at school (in the past 7 days) & Yes & $350(43.5)$ \\
\hline & & No & $479(56.5)$ \\
\hline & Passive smoking in public places (in the past 7 days) & Yes & $591(71.1)$ \\
\hline & & No & $238(28.9)$ \\
\hline & Father's current smoking & Yes & $402(46.8)$ \\
\hline & & No & $427(53.2)$ \\
\hline & Mother's current smoking & Yes & $39(4.5)$ \\
\hline & & No & $790(95.5)$ \\
\hline & Sibling's current smoking & Yes & $114(12.8)$ \\
\hline & & No & $715(87.2)$ \\
\hline & Close friend's current smoking & Yes & $790(94.5)$ \\
\hline & & No & $39(5.5)$ \\
\hline & Perceived academic achievement (in the past year) & High & $218(25.2)$ \\
\hline & & Middle & $216(27.0)$ \\
\hline & & Low & $395(47.8)$ \\
\hline & Perceived family socioeconomic status & High & $305(36.8)$ \\
\hline & & Middle & $378(46.1)$ \\
\hline & & Low & $146(17.1)$ \\
\hline
\end{tabular}

*Unweighted; ${ }^{\dagger}$ Weighted. 
Table 3. Biological, Psychological, and Social Factors Associated with Smoking Cessation Attempts among Adolescents Who Engaged in Intermittent and Light Smoking; Bivariate and Multivariate Analysis

\begin{tabular}{|c|c|c|c|c|c|c|c|c|}
\hline \multirow[t]{2}{*}{ Variables } & & \multirow[t]{2}{*}{ Categories } & \multicolumn{3}{|c|}{$\begin{array}{c}\text { First step: } \\
\text { bivariate analysis }\end{array}$} & \multicolumn{3}{|c|}{$\begin{array}{l}\text { Second step: } \\
\text { multivariate analysis }\end{array}$} \\
\hline & & & OR & $95 \% \mathrm{CI}$ & $p$ & $\mathrm{aOR}$ & $95 \% \mathrm{CI}$ & $p$ \\
\hline \multirow{3}{*}{$\begin{array}{l}\text { Biological } \\
\text { characteristics }\end{array}$} & Gender (ref.: boy) & Girl & 0.76 & $0.56 \sim 1.02$ & .068 & 0.63 & $0.35 \sim 1.12$ & .116 \\
\hline & Grade (ref.: 3rd) & 1 st & 1.30 & $0.91 \sim 1.87$ & .154 & 1.38 & $0.79 \sim 2.43$ & .262 \\
\hline & & 2nd & 1.10 & $0.78 \sim 1.56$ & .591 & 1.02 & $0.58 \sim 1.80$ & .945 \\
\hline \multirow{7}{*}{$\begin{array}{l}\text { Psychological } \\
\text { characteristics }\end{array}$} & Perceived body size (ref.: plump) & Normal & 0.99 & $0.70 \sim 1.39$ & .935 & & & \\
\hline & & Skinny & 0.88 & $0.62 \sim 1.26$ & .494 & & & \\
\hline & Subjective stress (ref.: high) & Low & 0.99 & $0.73 \sim 1.33$ & .939 & 0.88 & $0.47 \sim 1.66$ & .695 \\
\hline & & No & 1.28 & $0.84 \sim 1.94$ & .244 & 1.17 & $0.54 \sim 2.53$ & .700 \\
\hline & Depressive symptoms (ref.: yes) & No & 0.68 & $0.49 \sim 0.93$ & .015 & 0.63 & $0.37 \sim 1.10$ & .103 \\
\hline & Alcohol consumption (ref.: yes) & No & 1.17 & $0.83 \sim 1.63$ & .372 & & & \\
\hline & Vigorous physical activity (ref.: no) & Yes & 2.25 & $1.56 \sim 3.26$ & $<.001$ & 1.36 & $0.68 \sim 2.72$ & .385 \\
\hline \multirow{16}{*}{$\begin{array}{l}\text { Social } \\
\text { characteristics }\end{array}$} & Ease of purchasing cigarettes & Not easy and impossible & 0.89 & $0.64 \sim 1.25$ & .509 & & & \\
\hline & (ref.: easy) & Never tried & 0.73 & $0.42 \sim 1.27$ & .258 & & & \\
\hline & $\begin{array}{l}\text { Viewed an anti-smoking } \\
\text { advertisement (ref.: no) }\end{array}$ & Yes & 1.64 & $1.14 \sim 2.37$ & .008 & 2.59 & $1.45 \sim 4.62$ & .001 \\
\hline & $\begin{array}{l}\text { Participated in school-based } \\
\text { anti-smoking program (ref.: no) }\end{array}$ & Yes & 1.65 & $1.22 \sim 2.24$ & .001 & 1.14 & $0.69 \sim 1.89$ & .612 \\
\hline & $\begin{array}{l}\text { Read a warning label on a pack of } \\
\text { cigarettes (ref.: no) }\end{array}$ & Yes & 1.10 & $0.77 \sim 1.58$ & .587 & & & \\
\hline & Passive smoking at home (ref.: yes) & No & 0.84 & $0.60 \sim 1.18$ & .308 & & & \\
\hline & Passive smoking at school (ref.: yes) & No & 0.64 & $0.47 \sim 0.87$ & .005 & 0.68 & $0.42 \sim 1.10$ & .117 \\
\hline & $\begin{array}{l}\text { Passive smoking in public places } \\
\text { (ref.: yes) }\end{array}$ & No & 0.72 & $0.52 \sim 0.99$ & .046 & 1.03 & $0.58 \sim 1.80$ & .931 \\
\hline & Father's current smoking (ref.: yes) & No & 0.94 & $0.70 \sim 1.25$ & .655 & & & \\
\hline & Mother's current smoking (ref.: yes) & No & 1.30 & $0.65 \sim 2.60$ & .465 & & & \\
\hline & Sibling's current smoking (ref.: yes) & No & 1.11 & $0.73 \sim 1.69$ & .616 & & & \\
\hline & $\begin{array}{l}\text { Close friend's current smoking } \\
\text { (ref.: yes) }\end{array}$ & No & 0.48 & $0.25 \sim 0.93$ & .030 & 0.81 & $0.29 \sim 2.23$ & .682 \\
\hline & Perceived academic achievement & Middle & 0.94 & $0.69 \sim 1.27$ & .682 & & & \\
\hline & (ref.: low) & High & 0.88 & $0.57 \sim 1.35$ & .552 & & & \\
\hline & Perceived family socioeconomic & Middle & 1.12 & $0.76 \sim 1.67$ & .565 & 0.72 & $0.33 \sim 1.58$ & .407 \\
\hline & status (ref.: low) & High & 1.63 & $1.03 \sim 2.58$ & .036 & 0.63 & $0.27 \sim 1.47$ & .281 \\
\hline
\end{tabular}

ref.=Reference; $\mathrm{OR}=\mathrm{Odds}$ ratio; $\mathrm{Cl}=\mathrm{Confidence} \mathrm{interval;} \mathrm{aOR}=$ Adjusted odds ratio.

lihood of attempting to quit smoking. However, vigorous physical activity ( $\mathrm{OR}=2.25,95 \% \mathrm{CI}=1.56 \sim 3.26, p<.001)$ increased the likelihood of attempting to quit smoking. Among the social factors, having viewed an anti-smoking advertisement $(\mathrm{OR}=1.64,95 \% \mathrm{CI}=1.14 \sim 2.37, p=.008)$ and having participated in a school-based anti-smoking program (OR=1.65, 95\%
$\mathrm{CI}=1.22 \sim 2.24, p=.001$ ) were associated with higher likelihoods of smoking cessation attempts. Furthermore, having no passive smoking experiences at school $(\mathrm{OR}=0.64,95 \% \mathrm{CI}=0.47 \sim 0.87$, $p=.005)$ or in public places $(\mathrm{OR}=0.72,95 \% \mathrm{CI}=0.52 \sim 0.99, p=$ .046) was associated with a lower likelihood of attempting to quit smoking. Having a close friend who was a current 
smoker $(\mathrm{OR}=0.48,95 \% \mathrm{CI}=0.25 \sim 0.93, p=.030)$ was associated with a higher likelihood of attempting to quit smoking. Lastly, high perceived family socioeconomic status ( $\mathrm{OR}=1.63$, 95\% CI=1.03 2.58, $p=.036$ ) was linked to a higher likelihood of attempting to quit smoking.

In the multivariate analysis that included the variables found to be statistically significant in the bivariate analysis-including two biological variables, three psychological variables, and six social variables-having viewed an anti-smoking advertisement (adjusted OR=2.59, 95\% CI=1.45 4.62, $p=.001$ ) was significantly associated with a higher likelihood of attempting to quit smoking (Table 3).

\section{DISCUSSION}

The purpose of this study was to identify factors associated with attempts to stop smoking among Korean high school students who were currently intermittent and light smokers. In the bivariate analysis, vigorous physical activity had a positive association with smoking cessation attempts. Similarly, in another study of Korean high school students, physical activity was effective for decreasing smoking intentions [19]. According to Audrain-McGovern, Rodriguez, and Moss [20], physical activity influences neuroanatomical structures and intracellular signaling molecules, as well as the neurotransmitters that maximize the effects of substance abuse. In other words, physical activity relieves smoking intentions by influencing neural adaptations to continued smoking and the psychological rewards of smoking [20]. Along these lines, the authors [20] also proposed that the value of smoking might decrease if the rewards obtained from smoking could be replaced with the rewards obtained from physical activity, which is linked to decreased smoking frequency and intensity and to smoking cessation. Thus, the development of strategies to promote physical activity at home, in school, and in communities could be emphasized as a way to help adolescents stop smoking.

In addition, the present study revealed that having no depressive symptoms showed a negative association with smoking cessation attempts. A previous study found that depressive symptoms induced and promoted factors related to smoking and disturbed smoking cessation attempts [9]. However, Cooper et al. [21] reported that depressive symptoms were positively associated with smoking cessation attempts and proposed that, although increased negative attitudes toward and negative social perceptions of smoking influence smoking cessation attempts, they might lead to these depressive symptoms. In particular, in Korea's Confucian culture, which perceives smoking as an exclusively adult behavior, when adolescents who smoke experience emotional discom- fort-such as guilty feelings and depressive symptoms- the Confucian influence might encourage them to engage in socially expected behaviors, such as smoking cessation [17]. Thus, improving adolescents' understanding of social expectations regarding smoking might help them to make more frequent smoking cessation attempts.

Of the social factors, having viewed an anti-smoking advertisement, having participated in school-based anti-smoking programs, having experienced passive smoking at school and in public places, having a close friend who currently smoked, and high perceived family socioeconomic status were positively associated with smoking cessation attempts. Regarding having viewed anti-smoking advertisements, the results from this study support previous research on Korean adolescent smokers, which found that anti-smoking advertisements significantly increased smoking cessation attempts [15]. Yim and Park [9] reported that exposure to anti-smoking advertisements was positively related to smoking cessation attempts, with a stronger relationship observed among light than heavy (more than 10 cigarettes per day) adolescent smokers. Antismoking messages about the serious physical risks of smoking significantly increased the smoking cessation intentions of high school students by increasing their negative attitudes toward smoking, and subsequently directly influenced smoking cessation [22]. These anti-smoking messages and negative images of smokers increased adolescents' awareness of negative perceptions of smoking in public and social expectations about smoking cessation [23], which lessened the attractiveness of smoking and increased negative attitudes toward it [22]. Thus, healthcare professionals, including school and community nurses, should develop advertising content and strategies that target adolescents.

In addition, students who participated in school-based anti-smoking programs were more likely to quit smoking. This result is supported by previous research showing that participation in school-based anti-smoking programs increased adolescents' smoking cessation attempts $[10,15]$. In particular, awareness of the short-term physical hazards of smoking from participating in school-based anti-smoking programs is known to further increase the strength of negative attitudes toward smoking [22]. Therefore, considering that negative attitudes about smoking exert a direct influence on smoking cessation attempts, participating in school-based anti-smoking programs might indirectly influence the formation of negative attitudes toward smoking, which might in turn contribute to more smoking cessation attempts by high school students. Thus, increasing the number of qualitative smoking cessation programs should be emphasized in schools to motivate adolescents to try to stop smoking.

Passive smoking in schools and public places and by close 
friends increased the likelihood of attempting to quit smoking. Intermittent and light adolescent smoking is usually motivated by a desire to relate to peers who smoke and/or by recommendations from close friends who smoke, and the behavior is not about nicotine addiction or acting out [10]. However, Korean cultural norms define adolescent smoking as a provocative delinquent behavior [4]. Since social norms are strong determinants of intentions and behaviors in Korea, a nation that emphasizes collectivism [24], negative social perceptions of smoking might significantly encourage smoking cessation attempts. Thus, observing friends smoking in school or public places helps adolescents recognize that smoking deviates from social expectations, which makes them feel guilty about smoking. According to Choi [17], guilty feelings about smoking trigger the desire to quit smoking, and smoking-related guilt might be used as an effective smoking cessation strategy. Thus, for intermittent and light smokers to quit smoking, it is important that they clearly understand social perceptions and expectations about adolescent smoking.

Regarding the relationship between perceived family socioeconomic status and smoking cessation attempts, this study showed that adolescents who had a perceived high socioeconomic status were more likely to try to quit smoking. A previous study found that low socioeconomic status was related to a higher risk of smoking [25]. We know that the rate of smoking among low-income parents is higher than that among high-income parents, and that parental smoking exerts a modeling effect on adolescents and increases adolescents' expectations that their family will be accepting of smoking [25]. Adolescents with a low perceived family socioeconomic status also are less likely to receive material and emotional support for smoking cessation intervention programs or specialized treatments than adolescents with a high perceived familial socioeconomic status [26]. Thus, schools and community healthcare providers need to increase the frequency of anti-smoking activities and to augment policies and strategies aimed at increasing the rate of smoking cessation attempts in adolescents with low perceived familial socioeconomic status.

In an analysis of all of the statistically significant factors found in the bivariate analysis, the respondents who had viewed an anti-smoking advertisement were about two and a half times as likely as those who had not seen an advertisement to try to quit smoking during the past year. This result might reflect confounding relationships between variables. In other words, the fact that statistical significance disappeared for the relationship between physical activity and smoking cessation attempts in the multivariate analysis might be explained by adolescents increasing their physical activity to help with smoking cessation and having decreased smoking intentions following an increase in their motivation to stop smoking induced by seeing anti-smoking advertisements. According to Bernard et al. [19], in a study of high school students, the influence of physical activity on smoking cessation was controlled by motivation for smoking cessation, and the self-motivation for smoking cessation that encouraged physical activity was improved through anti-smoking advertisements [27].

Moreover, regarding the disappearance of statistical significance in the multivariate analysis for the relationship between depressive symptoms and smoking cessation attempts, adolescents who viewed anti-smoking advertisements might be more aware of the negative effects of smoking on their health, the negative perceptions of smokers in public, and the social expectations about smoking cessation. These factors might induce depressive symptoms associated with guilty feelings related to smoking [9]. In these contexts, viewing an anti-smoking advertisement might control the relationship between depressive symptoms and smoking cessation attempts.

Regarding the disappearance of statistical significance in the multivariate analysis for the relationship between having participated in school-based anti-smoking programs and smoking cessation attempts, school-based anti-smoking programs might be part of anti-smoking campaigns. Thus, most adolescents who participated in school-based anti-smoking programs might have also viewed anti-smoking advertisements. According to Hong et al. [28], high school students usually could not dedicate special time to anti-smoking campaigns because they spent most of their day on academic activities. Thus, they most often tended to be exposed to school-based anti-smoking campaigns, rather than anti-smoking programs conducted outside of school [28]. In light of this connection, the significance of having viewed anti-smoking advertisements for smoking cessation attempts among adolescents might also involve significant experiences of participating in school-based anti-smoking programs.

Furthermore, regarding the disappearance of statistical significance in the multivariate analysis for the relationships of having experienced passive smoking at school or in public and having a close friend who was a current smoker with smoking cessation attempts, a possible explanation is that adolescents might directly understand the negative effects of smoking when their close friends smoke or they experience secondhand smoke in school and in public. In a previous study, recognition of the harm that passive smoking causes others increased intentions to cease smoking [29]. In the same vein, Glantz and Jamieson [29] recommended augmenting educational interventions to improve students' recognition of the effects of passive smoking on others (for example, nonsmokers). 
Finally, adolescents' understanding of the need to stop smoking after viewing anti-smoking advertisements might increase their self-motivation to stop smoking, regardless of how much support they receive from their parents in families with low socioeconomic status. According to Durkin, Biener, and Wakefield [30], emotionally evocative anti-smoking advertisements designed to increase self-motivation have interaction effects with socioeconomic status, as their study found that anti-smoking advertisements were effective in reducing the significance of the influence of socioeconomic status on smoking cessation [30].

This study had several limitations, First, it used secondary data that did not include all of the possible psychosocial factors relevant for smoking cessation, such as those related to social norms about smoking, images of smokers in mass media, and parental and familial attitudes toward smoking. Thus, more studies aiming to identify further psychosocial factors associated with adolescents' smoking cessation are needed. Second, this study's sample comprised only Korean high school students who engaged in intermittent and light smoking. Since the psychosocial factors related to smoking cessation might differ for adolescents who smoke more, future studies should compare adolescent smokers regarding smoking quantity and intensity.

\section{CONCLUSION}

This study focused on the psychosocial factors associated with smoking cessation attempts among Korean high school students whose smoking was intermittent and light. Our results support previous studies' findings about the value of anti-smoking advertisements for smoking cessation among Korean high school students. To encourage smoking cessation among adolescents who are not heavy smokers, healthcare professionals-including school and community nurses-should employ anti-smoking advertisements and develop advertising content and strategies that target adolescents.

\section{Conflict of interest}

No existing or potential conflict of interest relevant to this article was reported.

\section{REFERENCES}

1. U.S. Department of Health and Human Service (USDHHS). The health consequences of smoking-50 years of progress: A report of the surgeon general [Internet]. Atlanta(GA): Centers for Disease Control and Prevention; 2014 [cited 2019 March 23]. Available from: https://www.ncbi.nlm.nih.gov/books/NBK179276/
2. Ministry of Education; Ministry of Health and Welfare; Korea Centers for Disease Control and Prevention. The 14th Korea youth risk behavior survey. Guidelines Report. Cheongju: Korea Centers for Disease Control and Prevention; 2018. Report No.: 117058.

3. Amrock SM, Weitzman M. Adolescents' perceptions of light and intermittent smoking in the United States. Pediatrics. 2015;135(2): 246-254. https://doi.org/10.1542/peds.2014-2502

4. Ra JS, Kim HS, Cho YH. Factors associated with intermittent and light smoking among Korean high school students: Intermittent and light smoking among Korean adolescents. Journal of Korean Academy of Community Health Nursing. 2018;29(1):33-40. https://doi.org/10.12799/jkachn.2018.29.1.33

5. Wang M, Zhong JM, Fang L, Wang H. Prevalence and associated factors of smoking in middle and high school students: A school-based cross-sectional study in Zhejiang Province, China. BMJ Open. 2016;6(1):e010379. https://doi.org/10.1136/bmjopen-2015-010379

6. Schane RE, Ling PM, Glantz SA. Health effects of light and intermittent smoking. Circulation. 2010;121(13):1518-1522. https://doi.org/10.1161/CIRCULATIONAHA.109.904235

7. Shiffman S. Light and intermittent smokers: Background and perspective. Nicotine and Tobacco Research. 2009;11(2):122-125. https://doi.org/10.1093/ntr/ntn020

8. Swayampakala K, Thrasher JF, Hardin JW, Titus AR, Liu J, Fong GT, et al. Factors associated with changing cigarette consumption patterns among low-intensity smokers: Longitudinal findings across four waves (2008-2012) of ITC Mexico Survey. Addictive Behaviors Reports. 2018;8:154-163. https://doi.org/10.1016/j.abrep.2018.10.002

9. Yim SY, Park MH. Comparison of the factors affecting smoking quit attempts in adolescent smokers according to amount of smoking. Journal of the Korea Contents Association. 2017;17(7): 622-633. https://doi.org/10.5392/JKCA.2017.17.07.622

10. Rubinstein ML, Rait MA, Sen S, Shiffman S. Characteristics of adolescent intermittent and daily smokers. Addictive Behaviors. 2014; 39(9):1337-1341. https://doi.org/10.1016/j.addbeh.2014.04.021

11. Hatala AR. The status of the "biopsychosocial" model in health psychology: Towards an integrated approach and a critique of cultural conceptions. Open Journal of Medical Psychology. 2012;1(4): 51-62. https://doi.org/10.4236/ojmp.2012.14009

12. Kim SR. Influencing factors on smoking quit attempts in adolescent smokers: Comparison between daily smokers and non-daily smokers [dissertation]. Seoul: Seoul National University; 2016. p. 1-69.

13. Lee B. Investigation of smoking behavior and quitting attempts in Korean adolescent smokers guided by the problem behavior theory [dissertation]. Seoul: Ewha Womans University; 2016. p. 1-98.

14. Park S, Suh G, Park S, Chung J. Factors affecting attempts to quit smoking in smoking high school students. Journal of the Korea Institute of Youth Facility and Environment. 2018;16(1):155-165. 
15. Park J. Factors affecting attempts to quit smoking in Korean adolescents. The Journal of the Korean Society of School Health. 2016;29(3):277-285. https://doi.org/10.15434/kssh.2016.29.3.277

16. Hoffman MA, Driscoll JM. Health promotion and disease prevention: A concentric biopsychosocial model of health status. In: Brown SD, Lent RW, editors. Handbook of counseling psychology. 3rd ed. Hoboken (NJ): John Wiley and Sons Inc.; 2000. p. 532-567.

17. Choi YJ. An exploratory study of the effectiveness of cigarette warning label: On the basis of the effects of fear, disgust, anger on attitudes and behavioral intention. Journal of Public Relations. 2014;18(1):151-187. https://doi.org/10.15814/jpr.2014.18.1.151

18. Bursac Z, Gauss CH, Williams DK, Hosmer DW. Purposeful selection of variables in logistic regression. Source Code for Biology and Medicine. 2008;3(1):17. https://doi.org/10.1186/1751-0473-3-17

19. Bernard P, Ninot G, Quantin X. Self-reported physical activity in smoking pre-cessation is not a protective factor against relapse for all. The American Journal on Addictions. 2015;24(2):153-159. https://doi.org/10.1111/ajad.12156

20. Audrain-McGovern J, Rodriguez D, Moss HB. Smoking progression and physical activity. Cancer Epidemiology, Biomarkers and Prevention. 2003;12(11):1121-1129.

21. Cooper J, Borland R, McKee SA, Yong HH, Dugué PA. Depression motivates quit attempts but predicts relapse: Differential findings for gender from the International Tobacco Control Study. Addiction. 2016;111(8):1438-1447. https://doi.org/10.1111/add.13290

22. Park J, Min S, Jang JY. A study on the influences of smoking expectancy-value and normative beliefs on nonsmoking behavioral intention. Journal of Public Relations. 2010;14(3):234-260. https://doi.org/10.15814/jpr.2010.14.3.234

23. Yang DJ. Exploring the communication effects of message framing of smoking cessation advertising on smokers' mental processes.
International Review on Public and Nonprofit Marketing. 2018;15 (3):315-332. https://doi.org/10.1007/s12208-018-0201-y

24. Fekadu Z, Kraft P. Self-identity in planned behavior perspective: Past behavior and its moderating effects on self-identity-intention relationships. Social Behavior and Personality: An International Journal. 2001;29(7):671-686.

https://doi.org/10.2224/sbp.2001.29.7.671

25. Kim J, Seo JH, Shin YJ, Kim C. The factors associated with smoking behavior of low-income people. Health and Social Welfare Review. 2013;33(1):577-602. https://doi.org/10.15709/hswr.2013.33.1.577

26. Park D, Jang SN. Influence of parental socioeconomic status on stress, depression and suicidal ideation among Korean adolescents. Journal of the Korea Academia-Industrial cooperation Society. 2013;14(6):2667-2676. https://doi.org/10.5762/KAIS.2013.14.6.2667

27. Blank MD, Ferris KA, Metzger A, Gentzler A, Duncan C, Jarrett T, et al. Physical activity and quit motivation moderators of adolescent smoking reduction. American Journal of Health Behavior. 2017;41(4):419-427. https://doi.org/10.5993/AJHB.41.4.6

28. Hong T, Johnson CC, Myers L, Boris N, Brewer D, Webber LS. Process evaluation of an in-school anti-tobacco media campaign in Louisiana. Public Health Reports. 2008;123(6):781-789. https://doi.org/10.1177/003335490812300614

29. Glantz SA, Jamieson P. Attitudes toward secondhand smoke, smoking, and quitting among young people. Pediatrics. 2000;106(6):e82. https://doi.org/10.1542/peds.106.6.e82

30. Durkin SJ, Biener L, Wakefield MA. Effects of different types of antismoking ads on reducing disparities in smoking cessation among socioeconomic subgroups. American Journal of Public Health. 2009; 99(12):2217-2223.

https://doi.org/10.2105/AJPH.2009.161638 